\title{
Molecular magnetic resonance imaging (MRI) of inflamed myocardium using ferucarbotran in patients with acute myocardial infarction
}

\author{
Ali Yilmaz ${ }^{1 *}$, Sabine Rösch ${ }^{1}$, Karin Klingel ${ }^{2}$, Reinhard Kandolf ${ }^{2}$, Xavier Helluy ${ }^{3}$, Karl-Heinz Hiller ${ }^{3}$, Peter M Jakob ${ }^{3}$, \\ Udo Sechtem ${ }^{1}$
}

From 2011 SCMR/Euro CMR Joint Scientific Sessions

Nice, France. 3-6 February 2011

\section{Introduction}

Superparamagnetic iron oxide nanoparticle (SPIO)-based molecular imaging agents targeting macrophages have been developed and successfully applied in animal models of myocardial infarction.

\section{Purpose}

The purpose of this clinical trial was to investigate whether molecular magnetic resonance imaging (MRI) of macrophages using ferucarbotran (Resovist ${ }^{\circ}$ ) allows improved visualization of the myocardial (peri-)infarct zone compared to conventional gadolinium-based necrosis/fibrosis imaging in patients with acute myocardial infarction.

\section{Methods}

The clinical study NIMINI-1 was performed as a prospective, non-randomised, non-blinded, single agent phase III clinical trial. Twenty patients who had experienced either an acute ST-elevation or non-ST-elevation myocardial infarction (STEMI/NSTEMI) were included to this study. Following coronary angiography, a first baseline cardiovascular magnetic resonance (CMR) study (pre-SPIO) was performed within seven days after onset of cardiac symptoms. A second CMR study (postSPIO) was performed either $10 \mathrm{~min}, 4 \mathrm{~h}, 24 \mathrm{~h}$ or $48 \mathrm{~h}$ after ferucarbotran administration. The CMR studies comprised cine-CMR, T2-weighted "edema" imaging, T2*-weighted cardiac imaging and T1-weighted lategadolinium-enhancement (LGE) imaging.

\section{Results}

The median extent of short-axis in-plane LGE was $28 \%$ (IQR 19-31\%). Following Resovist ${ }^{\circ}$ administration the median extent of short-axis in-plane $\mathrm{T} 2 \%$-weighted hypoenhancement (suggestive of intramyocardial hemorrhage and/or SPIO accumulation) was $0 \%$ (IQR 0-9\%; $\mathrm{p}=0.68$ compared to pre-SPIO). A significant in-slice increase $(>3 \%)$ in the extent of $\mathrm{T} 2 \%$-weighted "hypoenhancement" (post-SPIO compared to pre-SPIO) was seen in $6 / 16$ patients $(38 \%)$. However, no patient demonstrated "hypoenhancement" in T2*-weighted images following Resovist ${ }^{\circ}$ administration that exceeded the area of LGE.

\section{Conclusions}

T2/T2*-weighted MRI aiming at non-invasive myocardial macrophage imaging using the approved dose of ferucarbotran does not allow improved visualization of the myocardial (peri-) infarct zone compared to conventional gadolinium-based necrosis/fibrosis imaging.

\section{Author details}

${ }^{1}$ Robert-Bosch-Krankenhaus, Stuttgart, Germany. ${ }^{2}$ Department of Molecular Pathology, Tübingen, Germany. ${ }^{3}$ University of Würzburg, Würzburg, Germany.

Published: 2 February 2011

doi:10.1186/1532-429X-13-S1-P149

Cite this article as: Yilmaz et al:: Molecular magnetic resonance imaging (MRI) of inflamed myocardium using ferucarbotran in patients with acute myocardial infarction. Journal of Cardiovascular Magnetic Resonance 2011 13(Suppl 1):P149.

${ }^{1}$ Robert-Bosch-Krankenhaus, Stuttgart, Germany

Full list of author information is available at the end of the article

C 2011 Yilmaz et al; licensee BioMed Central Ltd. This is an open access article distributed under the terms of the Creative Commons 